\title{
HFE gene mutations analysis in Basque hereditary haemochromatosis patients and controls
}

\author{
M$^{\mathrm{a}}$ Dolores de Juan*,1, Ana Reta ${ }^{1}$, Agustin Castiella ${ }^{2}$, Jasone Pozueta ${ }^{1}$, Alvaro Prada ${ }^{1}$ and \\ Emilio Cuadrado ${ }^{1}$ \\ ${ }_{1}^{1}$ Immunology section, Laboratorio Unificado Donostia, Complejo Hospitalario Donostia, San Sebastián, Spain; \\ ${ }^{2}$ Gastroenterology Service, Hospital de Mendaro, Guipuzcoa, Spain
}

\begin{abstract}
$\mathrm{C} 282 \mathrm{Y} / \mathrm{C} 282 \mathrm{Y}$ genotype is the prevalent genotype in Hereditary Haemochromatosis $(\mathrm{HH})$, however, other genotypes have been associated with the disease. The objective of our study was to analyse the frequency of the three main mutations of HFE gene in $\mathrm{HH}$ patients and controls from the Basque population with differential genetic characteristics. Thirty five $\mathrm{HH}$ patients and 116 controls were screened for C282Y, H63D and S65C mutations using a PCR - RFLP technique. The association of HLA-A and-B alleles and HFE mutations was also studied in Basque controls. The frequency of $\mathrm{C} 282 \mathrm{Y}$ homozygotes in the group of patients was only $57 \%$. The rest of the patients presented heterogeneous genotypes, including compound heterozygotes: $11 \%$ of them were $\mathrm{C} 282 \mathrm{Y} / \mathrm{H} 63 \mathrm{D}$; and $2.85 \%$ were H63D/S65C. H63D or S65C heterozygotes had a frequency of $11 \%$ and 2.85 respectively and $5.71 \%$ patients lacked any mutation The high frequency of H63D in the healthy Basque population is confirmed in this study. A considerable incidence of $\mathrm{S65C}$ is observed either in controls and in $\mathrm{HH}(3 \%)$ or in iron overloaded patients. The peculiar genetic characteristics of Basques could explain the heterogeneity of genotypes in $\mathrm{HH}$ patients of this group. Further studies should be carried out to confirm these findings although the implication of other genetic or external factors in the development of $\mathrm{HH}$ is suggested.

European Journal of Human Genetics (2001) 9, 961 -964.
\end{abstract}

Keywords: haemochromatosis; HFE gene; H63D mutation

\section{Introduction}

Hereditary haemochromatosis $(\mathrm{HH})$ is a very common autosomal recessive disease with especially high prevalence in northern European populations. The disease affects the iron metabolism, the excess of body iron accumulates in the liver and other organs resulting in liver damage and other clinical disorders eg cirrhosis and hepatocellular carcinoma which can be prevented by early diagnosis and treatment with flebotomy.

*Correspondence: $M^{\mathrm{a}}$ Dolores de Juan, Immunology section, LUD, Complejo Hospitalario Donostia, Alto de Zorroaga s/n 20014 San Sebastián, Guipuzcoa, Spain. Tel: 3443 007040; Fax: 3443 007112; E-mail:mddejuan@chdo.osakidetza.net.

Received 14 June 2001; revised 12 September 2001; accepted 18 September 2001
In 1976, Simon et al discovered that the genetic predisposition cosegregated with HLA-A3 allele indicating its closing link to HLA. ${ }^{1}$ In 1996 , the haemochromatosis gene HFE was cloned. ${ }^{2}$ The HFE gene product is a major histocompatibility complex (MHC) class I-like molecule that binds $\beta 2$ microglobulin. It appears to complex with the transferrin receptor lowering its affinity for transferrin. Two causative mutations have been described in HFE gene. The main one results in a substitution of a tyrosine for a cysteine at 282 position (C282Y). The second results in an aspartic acid for a histidine at position 63 of the protein (H63D). Several studies have demonstrated that C282Y mutation disrupts the interaction between HFE molecule and $\beta 2$ microglobulin and its cell surface localisation whereas H63D change do not avoid the protein to be expressed but could simply impair its interaction with the transferrin receptor. ${ }^{3}$ 
$\mathrm{C} 282 \mathrm{Y}$ is the most prevalent mutation in $\mathrm{HH}$ patients. Between 60 and 100\% of patients are homozygous for this mutation with a decreasing gradient from north to south. ${ }^{4}$ Among the patients that are not homozygous for C282Y there are: compound heterocygotes; H63D homocygotes; C282Y heterozygotes and H63D heterozygotes. Between $4-$ $20 \%$ of $\mathrm{HH}$ patients have neither of these mutations. The HFE gene of many of these patients have been sequenced and most times no other mutations have been found. However other mutations or variants have been described in HFE gene either in iron overload conditions or in healthy individuals. Among them, S65C, an adenine to thymine transversion (193 A to T) which results in a conservative substitution have been found in several series of patients and may be implicated in the development of a milder form of $\mathrm{HH}^{5}$

Frequency of the main mutations in $\mathrm{HH}$ : H63D and $\mathrm{C} 282 \mathrm{Y}$ have been studied in a complete study with populations worldwide. ${ }^{6}$ This study showed that whereas $\mathrm{C} 282 \mathrm{Y}$ is restricted to European populations H63D has a more general distribution and its highest frequency is localised in the Basque population. The Basque population is considered to have genetic peculiarities as reported in many studies. ${ }^{7}$ Although its origin is controversial, it is generally accepted that Basques have mixed with invading populations to a lesser extent. ${ }^{8}$ Concerning the HLA system, where an HFE gene is located, substancial differences have been reported in HLA haplotypes and HLA allele frequencies when compared with other close populations. ${ }^{9}$

Our objectives are first, to study the frequency of the three main mutations in HFE gene: C282Y, H63D and S65C in a group of $\mathrm{HH}$ patients and controls from Basque origin and second study the interactions between HLA alleles and HFE mutations in this population.

\section{Patients and methods}

The group of patients consisted of 35 unrelated Basque individuals with primary haemochromatosis (25 men and 10 women) with a median age of 49 years (range: $26-71$ ). They presented a median ferritin value of $1121 \mu \mathrm{g} / \mathrm{l}$ (range: 350-3255); a median transferrin saturation percentage of 70 (range: 40-100\%); and a median serum iron of $175 \mathrm{mg} /$ dl (range:110-248). Six out of 35 patients had familial history of disease (first degree relatives). Patients with haematological disorders and other causes of iron overload were excluded from the study. The diagnosis of $\mathrm{HH}$ was based on clinical history and on having at least two of the following criteria: (1) increased tranferrin saturation, repeatedly greater than 50\%; (2) histological iron of grade III to IV and (3) hepatic iron index equal or greater than 1.9. ${ }^{10}$ In 12 cases, liver biopsy could not be done and the diagnosis of haemochromatosis was confirmed by the mobilisation of a total amount of iron greater than $4 \mathrm{~g}$ in phlebotomy. ${ }^{11}$ All healthy controls were recruited from the provincial blood donor bank. The Basque origin of this group was validated by their characteristic Basque surnames in the last three generations.

Genomic DNA was isolated from whole EDTA blood with QIAGEN (Germany) silicagel columns following the manufacturer's protocol. H63D, C282Y and S65C mutations were studied by PCR-RFLP technique with oligonucleotides described elsewere. ${ }^{6}$ Amplifications were performed in a Perkin Elmer thermocycler in standard conditions; annealing temperatures: $58^{\circ} \mathrm{C}$ for $\mathrm{H} 63 \mathrm{D}$ and $\mathrm{S} 65 \mathrm{C}$ and $61^{\circ} \mathrm{C}$ for $\mathrm{C} 282 \mathrm{Y}$. Then, PCR products were digested with Sau3AI (H63D)and RsaI (C282Y) and HinfI (S65C) and the result fragments were separated by electrophoresis in a $2.5 \%$ TBE agarose gel and detected by ethidium bromide staining.

Genotype and allele frequencies, together with 95\% of confidence limits, were estimated for the HFE mutations in both groups of patients $(n=35)$ and controls $(n=116)$ (Tables 1 and 2). HLA class I: -A, -B antigens were identifed by standard microlymphocytotoxicity technique and allele frequencies were calculated ${ }^{9}$ in a group of 84 controls. The existence of association or linkage disequilibrium between HFE mutations and HLA-A and B alleles was tested in the group of controls. The level of significance of those associations was calculated by $2 \times 2$ comparison tables and $P$ values were calculated using Yates corrected $\mathrm{Chi}^{2}$ and Fisher's tests. $P$ values were corrected according to the number of alleles compared. ${ }^{12}$

\section{Results}

Genotype frequencies were analysed in patients and control group and they are shown in Table 1. Only 20 out of 35 patients of this group (57\%) were found to be homozygous for $\mathrm{C} 282 \mathrm{Y}$ mutation. The rest of them presented heterogeneous genotypes: Four patients (11\%) were compound heterozygotes (H63D/C282Y); other four $(11 \%)$ were H63D heterozygotes and three (8\%) were C282Y carriers. S65C was found in two patients: one was a H63D/S65C compound heterozygote and the other one was a heterozygote for $\mathrm{S} 65 \mathrm{C}$ mutation only. Two out of 35 (5.71\%) lacked any of the three mutations studied.

S65C mutation, poorly studied in other populations, was also represented in control group with a $3 \%$ of allelic frequency (Table 2). This mutation was also found in eight other patients studied for HFE mutations due to different grades of iron overload based on biochemical and clinical grounds but without a liver biopsy or other criteria to diagnose $\mathrm{HH}$. Two of them were $\mathrm{S} 65 \mathrm{C} / \mathrm{C} 282 \mathrm{Y}$ herterozygotes; two were S65C/H63D and the other four were S65C heterozygotes.

H63D mutation presented a higher allelic frequency in Basque patients (13\%) when compared with Spanish ${ }^{13}$ and other Caucasoid series of patients from southern Europe but this increase is not significant when data were corrected for the number of $\mathrm{C} 282 \mathrm{Y}$ negative chromosomes :39\% H63D in Basque $\mathrm{HH}$ and $38 \%$ of average frequency in European patients series. ${ }^{4}$ This mutation is highly represented in our 
Table 1 Distribution of genotype frequencies in Basque patients and controls

\begin{tabular}{|c|c|c|c|c|c|c|}
\hline \multirow[b]{2}{*}{$H 63 D$} & \multirow[b]{2}{*}{$\mathrm{C} 282 \mathrm{Y}$} & \multicolumn{2}{|c|}{ Controls } & \multicolumn{2}{|c|}{ Patients } & \multirow[b]{2}{*}{$\%$} \\
\hline & & S65C & $\mathrm{n}$ & $\%$ & $\mathrm{n}$ & \\
\hline$-1-$ & $-1-$ & $-1-$ & 43 & 37.07 & 2 & 5.71 \\
\hline$+1-$ & $-1-$ & $-1-$ & 45 & 38.79 & 4 & 11.43 \\
\hline$-1-$ & $-1-$ & $-/+$ & 5 & 4.31 & 1 & 2.86 \\
\hline +/+ & $-1-$ & $-1-$ & 9 & 7.76 & 0 & - \\
\hline$-1-$ & $+/+$ & $-1-$ & 0 & - & 20 & 57.14 \\
\hline$+1-$ & $-1-$ & $+1-$ & 2 & 1.72 & 1 & 2.86 \\
\hline$-1-$ & $+1-$ & $+1-$ & 0 & - & 0 & - \\
\hline & Total & & 116 & & 35 & \\
\hline
\end{tabular}

Table 2 Mutations in the HFE gene: allele frequencies (\% 95\% confidence limits)

\begin{tabular}{lcc}
\hline & $\begin{array}{c}\text { Controls } \\
\mathrm{n}=116\end{array}$ & $\begin{array}{c}\text { Patients } \\
\mathrm{n}=35\end{array}$ \\
\hline H63D & $29.31(22.6-43)$ & $12.85(6.06-23.01)$ \\
C282Y & $5.17(2.8-8.7)$ & $67.14(54.88-77.91)$ \\
S65C & $3.01(1.3-6.2)$ & $2.85(0.35-9.94)$ \\
\hline
\end{tabular}

Basque control group (29.31\%). H63D seemed to be associated to HLA-A29 and B44 alelles in the group of Basque controls ( $P=0.03$ and $P=0.05$ respectively) although the level of significance is lost when $P$ values are corrected according to recommendations for multiple comparisons statistics in HLA studies. ${ }^{12}$ HLA-A29-B44 is a very frequent haplotype in Basques with a high linkage disequilibrium value. ${ }^{9}$

From the clinical point of view, there were not differences between the expression of the disease between $\mathrm{HH}$ individuals carrying an homozygous mutation and others not carrying characteristic HFE mutations.

\section{Discussion}

We analysed HFE mutations in a group of $35 \mathrm{HH}$ patients and 116 healthy controls from the Basque population. A noteworthy point from this work was the low frequency of $\mathrm{C} 282 \mathrm{Y}$ homozygotes in the group of patients (57.1\%). This result differs from those relating to populations from northern Europe ${ }^{4}$ and also from Spanish series ${ }^{13,14}$ in which the percentage of $\mathrm{C} 282 \mathrm{Y}$ homozygotes reached $80-90 \%$. The $\mathrm{HH}$ patients, non homocygous for $\mathrm{C} 282 \mathrm{Y}$ presented a great heterogenety of genotypes and a $6 \%$ of patients lacking any mutation (Table 1). Given the high number of normal HFE genes in our group of $\mathrm{HH}$, we compared HFE haplotypes in these patients diagnosed without biopsy (12/35) with those having a classical diagnostic based on liver biopsy: 10 out of 12 were $\mathrm{C} 282 \mathrm{Y}$ homozygotes, thus confirming a correct diagnosis of the disease.
In this study, H63D mutation had an allele frequency of $39 \%$ in patients and $31 \%$ in controls when data were corrected for the number of C282Y negative chromosomes. $\mathrm{H} 63 \mathrm{D}$ frequency in patients is similar to the $38 \%$ average frequency in European patients series but it is only slightly increased in our patients versus controls due to the high frequency of H63D in Basques. ${ }^{4}$ This data , already reported, is confirmed in our study with a larger group $(n=116)$ of controls. We found a 3\% allelic frequency for S65C mutation both in $\mathrm{HH}$ patients and controls in this study. Although these data argue against a significant pathogenic role of this mutation for $\mathrm{HH}$, we found a relative incidence of $\mathrm{S} 65 \mathrm{C}$ mutation in patients with moderate or severe iron overload. This group of patients should be systematically studied in the future in order to elucidate its real implication in hepatic iron overload. Several studies found S65C mutation in compound heterocygote states: S65C/C282Y and $\mathrm{H} 63 \mathrm{D} / \mathrm{C} 282 \mathrm{Y}$ in patients with a mild form of HH. ${ }^{5,1516}$

Although the group of patients studied is small $(n=35)$, the great heterogeneity of genotypes, different from the classical C282Y/C282Y, found in this series could reflect the heterogeneity of $\mathrm{HH}$ in Basque population with genetic singularities already described for other genes. ${ }^{17}$ Our data, have similarities with the results of $\mathrm{HH}$ in Italy ${ }^{18}$ and in the south of France $^{19}$ with a low frequency of C282Y homocygotes. These results and ours suggest the existence of other genetic factors possibly implicated in determining severity in iron overload and development of $\mathrm{HH}$ in heterozygotes or non mutated patients depending on the genetic background of the population studied.

Furthermore, recent studies about the allele expression of mutated HFE genotypes suggest a potential role of $\mathrm{H} 63 \mathrm{D}$ mutated protein in the increase of iron overload in H63D heterozygotes especially in compound heterozygotes. ${ }^{20}$ These authors postulate that in the presence of other acquired factors like heavy alcohol intake, chronic hepatitis $\mathrm{B}$ or $\mathrm{C}$ virus infectious, this mutation could enhance iron absorption and finally the development of $\mathrm{HH}$.

HLA system in proximity to HFE gene had been related to $\mathrm{HH}$ long before the description of HFE mutations by Feder $e t$ 
al. ${ }^{2}$ Many studies have confirmed the existence of a long (4 Mb) ancestral haplotype (HLA-A3, B7) associated with C282Y mutation with a probable Celtic origin. Concerning H63D mutation, Feder et al, reported that this mutation did not present linkage disequilibrium beyond $700 \mathrm{~Kb}$ centromeric of HFE gene. ${ }^{2}$ Other studies found H63D mutation mainly associated with a characteristic HFE caucasian haplotype defined by intragenic polymorphisms and tentatively assigned with an 'hispanic or mediterranean' origin. ${ }^{21}$ On the other hand, H63D was recently found associated to HLA-A29 haplotype in a group of patients with non classical Haemochromatosis of Portuguese (Iberian) origin ${ }^{22}$ and our results also suggest a link of H63D and HLA-A29B44 haplotype. A more exhaustive analysis of these HFE-H63D mutated haplotypes in our population could reveal a link between HLA-A29B44 alleles and the defined HFE-H63D 'hispanic' haplotype due to genetic recombinations in the past.

In conclusion, the peculiar genetic characteristics of the Basques could explain the heterogeneity of $\mathrm{HH}$ genotypes found in this study. Then, as others have also postulated, both the presence of other genetic or external factors could explain the appearance of a severe iron overload and $\mathrm{HH}$ in some of the H63D heterozygotes and no mutated genotypes. Further analysis of new genes, ie the recently described mutation in gene encoding ferroportin (SLC11A3), associated with dominant haemochromatosis, ${ }^{23}$ would be an interesting direction for future research.

\section{References}

1 Simon M, Bourel M, Fauchet R, Genetet B: Association of HLAA3 and B14 antigens with idiopathic hemochromatosis. Gut 1976; 17: 332-334.

2 Feder JN, Gnirke A, Thomas W et al: A novel MHC class I-like is mutated in patients with hereditary haemochromatosis. Nature Genet 1996; 13: 399-408.

3 Lebrón JA, Bennett MJ, Vaughn DE et al: Crystal structure of the hemochromatosis protein HFE and characterisation of its interaction with transferrin receptor. Cell 1998; 93: 111-123.

4 Merryweather-Clarke AT, Pointon JJ, Jouanolle AM, Rochette J, Robson KJH: Geography of HFE C282Y and H63D mutations. Genet Testing 2000; 4: 183-198.

5 Mura C, Raguenes O, Férec C: HFE mutations analysis in 711 hemochromatosis probands: evidence for S65C implication in mild form of hemochromatosis. Blood 1999; 93: 2502-2505.

6 Merryweather-Clarke AT, Pointon JJ, Shearman JD, Robson KJH: Global prevalence of putative haemochromatosis mutations. $J$ Med Genet 1997; 34: 275 - 278.

7 Calafell F, Bertranpetit J: Principal component analysis in gene frequencies and the origin of the Basques. Am J Phys Anthropol 1994; 93: 201-215.
8 Cavalli-Sforza LL: The Basque population ancient migrations in Europe. Munibe 1988; 6 (suppl): 129-137.

9 Martinez-Laso J, De Juan MD, Martinez Quiles N, Gomez Casado E, Cuadrado E, Arnaiz-Villena A: The contribution of the HLA-A, $-B,-C$ and DR, -DQ DNA typing to the study of the origins of Spaniards and Basques. Tissue Antigens 1995; 45: 237 - 245.

10 Adams P, Brissot P, Powell LW: EASL International Consensus Conference on Hemochromatosis. Expert Document. J Hepatol 2000; 33: 485-504

11 Powell LW, George DK, Mc Donell SM, Kowdley KV: Diagnosis of hemochromatosis. Ann Intern Med 1998; 129: 925 - 931.

12 Svejaard A, Ryder LP: HLA and disease associations: Detecting the strongest association. Tissue Antigens 1994; 43: 18-27.

13 Sanchez M, Brugera M, Bosch J, Rodés J, Ballesta F, Oliva R. Prevalence of the Cys282Tyr and His63Asp HFE gene mutations in Spanish patients with hereditary hemochromatosis and in controls. J Hepatol 1998; 29: 725 - 728.

14 Pardo A: Hemocromatosis Hereditaria (HH) en España. Impacto del diagnóstico genético. Gastroenterologia y Hepatologia 2001; 24: 112 .

15 Rochette J, Pointon JJ, Fisher CA et al: Multicentric origin of hemachromatosis gene (HFE) mutations. Am J Hum Genet 1999; 64: $1056-1062$.

16 Barton JC, Sawada-Hirai R, Rothenberg BE, Acton R: Two novel missense mutations of the HFE gene (I105C and G93R) and identification of the S65C mutation in Alabama hemochromatosis probands. Blood Cells Mol Dis 1999; 25: 147-155.

17 Casals T, Vazquez C, Lazaro C, Girbau E, Gimenez FJ, Estivill X: Cystic Fibrosis in the Basque country: High frequency of mutation $\Delta \mathrm{F} 508$ in patients of Basque origin. Am J Hum Genet 1992; 50: 404-410.

18 Piperno A, Sampietro M, Pietrangelo A et al: Heterogeneity of hemochromatosis in Italy. Gastroenterology 1998; 114: 9961002.

19 Mercier G, Burckel A, Bathelier C, Boillat E, Lucotte G: Mutation analysis of the HLA-H gene in French hemochromatosis patients and genetic counseling in families. Genet Couns 1998; 9: $181-186$.

20 Rosmorduc O, Poupon R, Nion I et al: Differential HFE allele expression in hemochromatosis heterozygotes. Gastroenterology 2000; 119: 1075 - 1086 .

21 Aguilar-Martinez P, Thelcide C, Jeanjean P, Masmejean C, Giansily M, Schved JF: Haplotype analysis of the HFE gene: Implications for the origins of hemochromatosis related mutations. Blood Cells, Molecules, and Diseases 1999; 15: $166-$ 169.

22 Porto G, Alves H, Rodrigues P et al: Major histocompatibility complex class I associations in iron overload: evidence for a new link between the HFE H63D mutation, HLA-A29, and non classical forms of hemochromatosis. Immunogenetics 1998; 47 : $404-410$.

23 Njajou OT, Vaessen N, Joosse M, Berghuis B, Van Dongen JWF, Breuning $\mathrm{M} \mathrm{H}$, et al: A mutation in SLC11A3 is associated with autosomal dominant hemochromatosis. Nature Genet 2001; 28: $213-214$. 